\title{
The future of Australian medical education: a focus on technology
}

\section{Technological approaches and increased use of simulation are elements of a more comprehensive solution to creating a fit-for-purpose medical workforce}

1 ustralia is undergoing considerable change in management of its health care systems. This is driven by the increase in complexity of patient illnesses and the public's higher expectations of having access to safe, high-quality health care. Central to the success of Australia's future health care systems will be the workforce that delivers health care services. Australia has increased the number of medical schools and accepted increased numbers of international medical graduates to address workforce shortages in medicine that have resulted from historical decisions. However, the increasing age of graduates, their shorter working weeks and, notwithstanding the recent increase in clinical placements, the limited amount of quality clinical time available per student, raise concerns about the sustainability of a well trained medical workforce. ${ }^{1}$ Equally significant as the reduction in clinical learning opportunities are the rapid rate of change in, and complexity of, treatments that junior medical officers will need to consider offering if the best interests of their patients are to be served.

Work is underway on many fronts to ensure Australia maintains the quality of our medical graduates. At junior doctor level, development of an Australian Curriculum Framework (ACF) has provided an outline of the competencies expected of a junior medical officer, ${ }^{2}$ giving Australian universities and accredited hospital and general practice prevocational trainers a guide for their medical program development. To help sustain the medical education and training infrastructure to cope with increasing throughput, federal funding is being invested in simulations to augment clinical placement. ${ }^{3}$ Medical schools are finding new clinical placement opportunities in private hospitals, general practice clinics and nursing homes. However, even more training capacity will be needed to meet Australia's future health care demands. Medical students require better scoping of what they need to learn; greater flexibility in how they learn; more appropriate timing in when they learn; and effective methods for managing their reflective practice so that they will retain learnt skills.

\section{The future of medical education}

Above all else, medical students will need to be adaptable lifelong learners. It is likely that health care will become increasingly complex as research expands the boundaries of medicine and increasing costs burden both the public and private systems. Changes in patient complexity, medical workforce demographics and the diversity of the broader workforce, as well as innovations in technology and treatment, will all affect the role of junior medical officers. The complexity of future changes suggests there is no simple single solution that will ensure the quality of our future medical workforce. We present what we see as the more important contributing factors in the technological domains.

The $\mathrm{ACF}^{2}$ underlines the scope of practice, which is expansive, and we cannot expect all incoming graduates to be competent at everything that should be undertaken by junior medical officers. What we should be able to expect is that they have knowledge of their own skill set and are able to effectively communicate their strengths and limitations to patients and other health care providers. For students to have conscious recognition of competency requires more than a framework and may include national standardised assessments, a standardised curriculum or at least competency standards for skills, behaviours and tasks against which to compare their own performance.

Getting the balance right between local innovation and national collaboration to provide our future medical workforce will require better modelling of Australia's health care needs. Clearly, there are some components of educational development that are better approached by national collaborations. Compelling examples include the use of technology to support education and the development of formative assessments (using simulated or authentic clinical environments) for procedures requiring psychomotor skills.

\section{Technology considerations for education}

\section{E-portfolios}

Society expects doctors to be lifelong learners who not only maintain a high level of competency in their scope of practice, but also continue to update their practice as better treatments arise. Internationally, there is a move to require doctors to provide evidence of maintaining their standards of practice. ${ }^{4}$ Similarly, there is a push for medical students to maintain a portfolio of experience and reflections. ${ }^{5}$ The use of e-portfolios to collect, store and share individual data will become an essential part of education throughout the continuum of medical practice. Although there are many definitions of e-portfolio ${ }^{6}$ it is likely that in the medical context e-portfolios will need to encompass: - assessment of performance standards defined by a recognised authority;

- compelling and accessible evidence of learning or achievement directed at specific audiences (employers, supervisors);

- ability to reflect and develop metacognition to plan learning and integrate diverse learning experiences; and 
- professional development planning, providing records of goals, learning, performances and achievements.

The value of e-portfolios will depend on how they are supported. Without standards for interoperability, the portability of information stored on e-portfolios will increase the owner's workload during the transition between educational and work environments, as well as across specialty domains.

\section{E-health}

With the development of electronic patient records there is an opportunity to provide automatic mapping between training and patient outcomes. This would require work within e-health, for example to enable access to records by health professions students while ensuring that patient information is protected. However, doctors around the world have been reviewing patient information to improve practice in many procedural areas for decades. Linking education with patient outcomes through e-records could potentially benefit both the individual doctor and the developers of educational material. Doctors would be better able to plan future learning activities to reflect areas of need, and educators could receive information about what could be used to increase the effectiveness of their training programs.

\section{E-learning}

Other emerging technologies include online learning (e-learning, virtual worlds and portable applications). These technologies have the potential to support selfdirected learning and provide greater student feedback, but will require scaled approaches to ensure feasibility. The computer industry has demonstrated the power of engagement through well designed virtual worlds and applications on portable devices, with millions of users engaging daily. Although current e-learning in health care is often quite limited in scope and sophistication, there are examples of good interactive material and processes ${ }^{7}$ including "serious games", which are designed for a primary purpose other than pure entertainment. Development of such games is currently costly because developing, validating and maintaining the quality of online learning is expensive if the target audience is small; however, when the cost of such products is spread across thousands of participants instead of hundreds, the cost is not only more affordable but the opportunity to validate training improves. One way to achieve such participant numbers is to develop these programs through large-scale collaboration where modules can be reused across disciplines and educational institutions.

\section{Simulation}

The advantage of engaging with technologies such as simulation is the guarantee that students receive exposure to particular experiences. For example, few medical or midwifery students will have the experience of observing serious complications when attending real births during their training; however, it is possible to provide a simulation program guaranteeing this exposure. ${ }^{8}$ A recent meta-analysis of technology-enhanced simulation ${ }^{9}$ demonstrated that this training was consistently superior to no intervention or traditional clinical attachment experience. It showed large effects for outcomes on knowledge (effect size, 1.20), skills (1.09-1.18), and speed (0.79), and a moderate effect for patient-related outcomes (0.50). The studies involved many professions and both undergraduate and continuing education. Interestingly, additional features and the quality of educational design of the intervention seemed to have no consistent impact. In other words, it was the simulation alone that seemed to provide the most consistent benefit, not how well or cleverly it was used. In simulation, students can also safely learn from their mistakes. Blended learning approaches using virtual worlds and other serious games can provide repeated exposure to meet different students' requirements when combined with face-to-face simulation or clinical placement.

\section{Standards and governance}

There is wide concern, although scant evidence in everything but the surgical disciplines, ${ }^{10,11}$ that students and junior doctors' "near patient" experience is diminishing. The risk of doing less learning by the bedside is that alternative forms of education delivery may not actually teach what we think they do. Therefore, there is a need to validate whether simulation and e-learning approaches do produce the expected knowledge, skills and behaviours in the student population when they practise in clinical areas. The Australian Society for Simulation in Healthcare, as part of Simulations Australia, is developing standards for simulations educators; ${ }^{12}$ however, governance over compliance still rests with the many universities and hospital systems around the country. As with e-portfolios, Australia needs to develop standards and guidelines to ensure that investing in health care e-learning includes providing effective access for learners. Where possible, health care organisations should catalogue available e-learning opportunities to avoid unnecessary duplication and increase exchange of resources.

Another necessary approach is to invest resources to demonstrate the transfer from educational programs to clinical settings. Such an approach should be effective for well defined skills (eg, procedural skills); however, it may be more difficult to validate programs for outcomes in the area of professional skills. A further approach is to expand the use of blended learning to provide educational opportunities for medical students and focus on assessing students during clinical practice. There is evidence that the transfer of intended learning objectives by senior doctors is poor during didactic teaching ${ }^{13}$ and that the reliability and quality of feedback provided to students and educational institutions during clinical placements is often questionable. ${ }^{14}$ Consequently, as the field of health care engages more with technology to provide medical education, there is a strong need to increase the quality of the supervision and assessment skills of our clinical educators. 


\section{Assessment, aptitude and choice}

Internationally, the scope of medical skills and behaviours that are formally assessed has increased, with the majority of formal assessments being used for accreditation to practice..$^{13}$ At present, we rely on clinical placement rotations to provide medical students with the experience to assess the alignment of their skills with their career choices. As clinical placements and educational opportunities contract in medicine, we must change the way we provide exposure, assessment and feedback to students so that they not only choose the right career path but are also able to pursue the appropriate education to get there. One way to do this is to increase the use of simulation.

In addition, aptitude assessments for surgical programs are already demonstrating measurable differences between individuals. ${ }^{15-17}$ Early exposure can be achieved, for example, by harnessing and sharing the experience of other students through e-portfolios and access to simulations programs designed to teach the fundamentals of specialties. By developing models of individuals' early learning of skills relevant to particular specialties, students could receive feedback on their aptitude for each specialty. Rather than using aptitude as a barrier to program selection, this information could be used by the students to help guide their selection. In cases where a student's desired career and aptitude for that career conflict, the student would be better able to pursue upskilling opportunities. Effectively, using simulation, aptitude assessments, and fast-tracking for students would eventually replace the varied internship, as has been successfully achieved in the Canadian system. ${ }^{18}$ The achievement of this would require involvement of all stages of education from undergraduate to specialty, and be guided by workforce imperatives.

\section{Conclusions}

Medical education must become more effective at using a broader range of learning opportunities to meet future training requirements. This will involve greater innovation in new types of clinical placement and better engagement with technology. Medicine must invest in the skills of educators and delivery systems to support lifelong learning. Critically, we should be investing in assessment to provide students and doctors with effective feedback on their performance.

\section{Competing interests: No relevant disclosures.}

Provenance: Commissioned; externally peer reviewed.

1 McGrath BP, Graham IS, Crotty BJ, Jolly BC. Lack of integration of medical education in Australia: the need for change. Med J Aust 2006; 184: 346-348

2 Confederation of Postgraduate Medical Education Councils. Australian curriculum framework for junior doctors. http://curriculum.cpmec. org.au (accessed Jun 2012)

3 Health Workforce Australia. National training plan - overview. 2011 http://www.hwa.gov.au/sites/uploads/national-training-planoverview-05-2011.pdf (accessed Jun 2012).

4 Saltman DC, Tavabie A, Kidd MR. The use of reflective and reasoned portfolios by doctors. J Eval Clin Pract 2012; 18: 182-185.

5 van Wesel M, Prop A. The influence of portfolio media on student perceptions and learning outcomes. Proceedings of the Student Mobility and ICT conference: can e-learning overcome barriers of lifelong learning? 2008 November 19-20; Maastricht; The Netherlands. Editors, Rienties B, Giesbers B, Gijselaers W. Maastricht: FEBA ERD Press, 2008: 73-80

6 Australian ePortfolio Project. ePortfolio use by university students in Australia: informing excellence in policy and practice. Final project report August 2008. http://www.eportfoliopractice.qut.edu.au/docs/ Aep_Final_Report/AeP_Report_ebook.pdf (accessed Jun 2102).

7 Hay PJ, Engstrom C, Green A, et al. Promoting assessment efficacy through an integrated system for online clinical assessment of practical skills. Assessment and evaluation in higher education 2012; (1): 1-16.

8 Régo P, Lyon P, Watson M. The impact of maternity crisis resource management training. Brit J Midwifery 2011; 19: 315-323.

9 David A, Cook DA, Hatala R, et al. Technology-enhanced simulation for health professions education. A systematic review and meta-analysis. JAMA 2011; 306: 978-988.

10 Parsons BA, Blencowe NS, Hollowood AD, et al. Surgical training: the impact of changes in curriculum and experience. J Surg Educ 2011; 68: 44-5l.

11 Blencowe NS, Parsons NA, Hollowood AD. Effects of changing work patterns on general surgical training over the last decade. Postgrad Med J 2011; 87: 795-799.

12 Australian Society for Simulation in Healthcare. Activities. http:// www.simulationaustralia.org.au/divisions/activities-2 (accessed Jun 2012).

13 Lautrette A, Schwebel C, Gruson D, et al. Transfer of take-home messages in graduate ICU education. Intensive Care Med 2011; 37: 1323-1330.

14 Epstein RM. Assessment in medical education. N Engl J Med 2007; 356: 387-396.

15 Carretta T, Ree MJ. General and specific cognitive and psychomotor abilities in personnel selection: the prediction of training and job performance. Int J Selection Assessment 2000; 8: 227-235.

16 Cope DH, Fenton-Lee D. Assessment of laparoscopic psychomotor skills in interns using the Mist Virtual Reality Simulator: a prerequisite for those considering surgical training? ANZ J Surg 2008; 78: 291-296.

17 Hoffman BM, Coons MJ, Kuo PC. Personality differences between surgery residents, nonsurgery residents, and medical students. Surgery 2010; 148: 187-193.

18 Medical Council of Canada. Recalibrating for the 2lst century: report of the Assessment Review Task Force of the Medical Council of Canada. Oct 2011. http://www.mcc.ca/en/Publications/assessment review_report.shtml (accessed May 2012) 